\title{
Hız-ve-durum sürtünme yasaları ve Burridge-Knopoff yay blok sistemi kullanılarak depremlerin dinamik modellenmesi
}

\author{
Eyüp Sopacı ${ }^{1 *}$ (iD \\ ${ }^{1}$ Orta Doğu Teknik Üniversitesi, Fen Bilimleri Enstitüsü, Jeodezi ve Coğrafi Bilgi Teknolojileri Bölümü, Çankaya, Ankara.
}

Öz: Depremlerin fiziksel oluşum mekanizmaları henüz tam anlamılla bilinememekle birlikte, kırılgan kabukta gerçekleştiği durumda büyük ölçüde sürtünme yasaları ile açıklanabilmektedir. Bu durumda depremler, tutma-bırakma hareketi sonucu oluşan sürtünme kararsızlı̆̆ının (frictional instability) bir sonucudur. Hiz-ve-Durum yasaları (Rate-and-State Friction law, RSF) ile doğadaki deprem olaylarına benzer artçı depremler, yavaş depremler, sismik ve sismik olmayan hareketler modellenebilmektedir. Bu çalışmada Dieterich, Ruina ve Perrin tipi RSF yasalart tek serbestlik dereceli Burridge-Knopoff (BK) yay-blok sistemine entegre edilerek irdelenmiştir. Modellemenin gerçekçi olması bakımından fay geometrisi ve fiziksel yapısı San Andreas/Parkfield fayına uygun olarak belirlenmiştir. Çalışmada kullanılan dinamik sistemler doğrusal olmayan sert (stiff) diferansiyel denklemlerden oluşmaktadır. Bu nedenle önerilen modellerin doğrusal olmayan karakteri ile çözümü için nümerik öneriler sunulmuştur. Modellere kararlılık analizi uygulanmış ve sistemin sürtünme kararlılığl (sismik olmayan hareket) ve kararsızlı̆̆ (sismik döngü) sergilediği kritik bölgeler belirlenmiştir. RSF parametre uzayl değiş̧tirilerek sadece sürtünme kararsızlığı sergilediği durumlar için sistem simüle edilmiştir. Yapılan çalışmalar sonucu RSF yasalarından kaynaklı sistemin oluşturacağı dinamiklerin büyüklügünün kararlılık eğrisinden sapma ile orantılı olduğu bulunmuştur. Bu eğriden sabit oranda sapma olduğunda ise sistemin aynı dinamikleri sergilediği görülmüştür. Yapılan literatür taramasında, bulunan ölçütün ilk kez bu çalı̧̧ma kapsamında elde edildiği belirlenmiştir. Bu çalışma, ileride depremleri tetikleyen güçsüz sinyallerin araştırılmasına fayda sağlayacaktır.

Anahtar Sözcükler: Deprem, Hız-ve-Durum sürtünme yasaları, Burridge-Knopoff, Jeodinamik, Doğrusal olmayan dinamikler

\section{Modelling of earthquakes by using Rate-and-State friction laws on the Burridge-Knopoff spring-block system}

Abstract: Although physical mechanism of earthquakes has not been clearly answered yet, it can be explained substantially with friction laws when the slip event subjects to the brittle crust. In such cases earthquakes are a result of frictional instability accompanied by stickand-slip motion. Earthquakes, foreshocks, aftershocks, slow slip events have been modelled by using Rate-And-State Friction (RSF) laws. In this study Dieterich, Ruina and Perrin type RSF laws have been studied on the Burridge-Knopoff (BK) spring-block system, which was originally proposed with a velocity dependent friction law. In order to comply with the reality, fault geometry and its physical structure are chosen appropriate to the San Andreas/Parkfield fault. Since the proposed systems are stiff nonlinear dynamics, they are offered with numeric procedure adapted to solve stiff differential equations. By applying stability analysis, the critical boundaries between stable and unstable sliding (seismic cycle) are determined. The model is simulated by tuning the RSF law parameters for unstable sliding regime. As a result of the studies it has been found that, the magnitude of the slip event is proportional to the distance from the curve which separates stable and unstable sliding regimes. Besides, when system parameters deviates with a fixed amount from the stability curve, the system shows the same dynamics. To the best of my knowledge, the defined criterion is being published for the first time within the scope of this work. This study will pave the way for further researches of earthquake and weak triggering effects.

Keywords: Earthquake, Rate-and-State friction law, Burridge-Knopoff, Geodynamics, Nonlinear dynamics 


\section{Giriş}

Depremlerin fiziksel mekanizmalarını ve onu etkileyen-tetikleyen etkilerini araştırmak için yay-blok sistemleri ve sürtünme yasaları etkin bir şekilde kullanılmaktadır. Burridge ve Knopoff (1967), yay ve bloklardan oluşan basit bir dinamik model ile laboratuvar testleri ve nümerik simülasyonlar gerçekleştirmiş ve gözlenen dinamiklerin doğada gözlenenlere ne kadar yakın olduklarını araştırmıştır. Blokların çekici bir hız ve sürtünme kuvveti etkisi altındaki hareketlerinin Gutenberg-Richter (GR) yasasına uyduğunu tespit etmiştir. Ancak, literatürde sadece hıza bağlı bir sürtünme yasasının gerçeği yeterince yansıtamadı̆̆ından bahsedilmektedir (Scholz, 1998; Marone, 1998). Sürtünmenin, hızın yanında sürtünen yüzeylerin birbirini tutabilme gücünü de temsil eden, durum parametresine bağlı olduğu yapılan laboratuvar testlerinde gösterilmiştir (Dieterich, 1979; Ruina, 1983; Perrin, Rice \& Zheng, 1995; Nagata, Nakatani \& Yoshida, 2012). Bu tür sürtünme yasalarına Hız-veDurum sürtünme yasaları (Rate-and-State Friction, RSF) denilmektedir.

Depremlerin sürtünme kararsızlığı nedeniyle oluşan tutma-bırakma hareketinden kaynaklandığı varsayılmaktadır. RSF yasaları ve basit bir yay-blok sistemi kullanarak sürtünme kararsızlığı (hız zayıflatıcı-sismik bölgeler) ve kararlı kayma hareketine (hız güçlendirici-sismik olmayan bölgeler, creeping) ait dinamikler oluşturulmaktadır. Bu dinamikler ile kosismik, post-sismik, artçı şoklar, yavaş depremler ve heyelan olayları, RSF parametrelerine bağlı olarak modellenebilmektedir (Marone, 1998). Laboratuvar ortamında oluşturulan bu yasaların gerçek doğaya uygulanması konusundaki tartışmalar devam etmektedir. Özellikle 2004 yılında meydana gelen Parkfield depremine ait kosismik ve post-sismik deformasyonlar RSF yasaları kullanılarak araştırılmıştır (Johnson, Burgmann \& Larson, 2006; Savage \& Langbein, 2008; Barbot, Fialko \& Bock, 2009; Helmstetter \& Shaw, 2009; Chang, Avouac, Barbot \& Lee, 2013). Bahsedilen çalışmalarda deprem sırasındaki ve özellikle sonrasındaki deformasyona ilişkin değerler jeodezik ve sismik veriler kullanılarak RSF temelli modeller ile kestirilmiştir. Kullanılan modeller ile deformasyona ait değerleri kestirmek aynı zamanda RSF'ye ait parametreleri kestirmek anlamına gelmektedir. Ancak aynı bölgede aynı veriler kullanılmasına rağmen kestirilen RSF parametreleri ciddi farklılıklar göstermektedir. Bu farklılıkların, laboratuvarda geliştirilen sürtünme yasalarının ölçek probleminden, faydaki gerilim ve sürtünme heterojenliğinin tam olarak bilinememesinden ve depremlerin karmaşık ilişkisinden kaynaklandığ düşünülmektedir. Ayrıca, Helmstetter ve Shaw (2009), basit bir yay-blok sistemi ve RSF yasaları kullanılarak çok sayıda RSF parametre kümesinin 2004 Parkfield deprem verilerine uygun olarak kestirilebildiğini belirtmektedir. Bunun yanında her ne kadar laboratuvarda benzer sonuçlar göstermiş olsalar da farklı RSF yasaları farklı dinamikler üretebilmektedir.

$\mathrm{Bu}$ çalışmada BK modeline Dieterich, Ruina ve Perrin tipi RSF yasaları entegre edilmiştir. Çalışılan modeller, deprem ve fiziksel mekanizması arasında ilişki kuran oldukça basit modellerdir. Bu şekilde yapılan basitleştirmelerin sebeplerinin başında, depremi etkileyen veya tetikleyebilecek bir kuvveti, diğer karmaşık ilişkilerden bağımsız olarak inceleyebilme fırsatı sunması gelmektedir (Kawamura, Ueda, Kaktui, Morimoto \& Yamamoto, 2017). Örneğin yakın ve uzak merkezde gerçekleşen depremlerin, başka depremleri tetikleyip tetiklemeyeceği sorusu, RSF yasası ile yürütülen tek serbestlik dereceli bir model ile test edilmiştir (Gomberg, Blanpied \& Beeler, 1997; Belardinelli, Bizzarri \& Cocco, 2003). Bu çalışmalarda deprem mekanizması sürtünme yasaları ile yürütülen basit bir yay-blok modeli ile tanımlanmış, dolayısıyla dışarıdan gelecek sismik yer hareketi ve gerilim seviyesinde değişikliğe neden olabilecek sinyaller, diğer karmaşık ilişkilerden bağımsız bir şekilde araştırılmış ve doğada gözlenenlerle karşılaştırılmıştır.

Bu çalışmada öncelikle BK modeli ve RSF yasaları sunulmuş ve denklemlere boyutsuzlaştırma işlemi uygulanmıştır. Temel alınan model, Ruina tipi bir sürtünme yasası ile Erickson, Birnir ve Lavallée (2008) tarafından sunulmuştur. Ancak Dieterich ve Perrin tipi yasalar ilk kez bu çalışmada önerilen modele entegre edilmiştir. Oluşturulan modellere doğrusal kararlılık (linear stability) analizi uygulanmıştır. Böylece sistemin kararlı (sismik olmayan) bir durumdan kararsız (sismik) bir duruma 
geçişi ile ilgili analitik bir denklem elde edilmiştir. Gu, Rice, Ruina ve Simon (1984) tarafından Ruina tipi RSF yasası için kararlılık analizleri basit bir yay-blok sistemi kullanarak ve atalet terimini göz ardı ederek detaylı bir şekilde yapılmıştır. Bu çalışmada farklı olarak kararlılık analizine atalet terimi de eklenmiştir. Kararlılık analizi sonucu elde edilen bağıntı ile RSF yasalarının kritik değerleri için karşılaştırmalar yapılmışıı. Daha sonra Ruina tipi RSF yasası kullanılarak ve sürtünme parametreleri değiştirilerek simülasyonlar yapılmıştır. Simülasyon sırasında fay geometrisi ve diğer özellikler sabit kabul edilerek sadece RSF parametrelerinin etkileri araştırılmıştır.

Bu çalışmanın amacı farklı RSF yasaları ve tek serbestlik dereceli bir BK modeli kullanarak oluşan dinamikleri araştırmaktır. Sistemin ne zaman sismik bir döngü veya kararlı bir kayma hareketi (creeping) sergileyeceği, gözlenen gerilim, hız, tekrarlanma süresi ve benzeri dinamiklerin hangi parametrelere bağlı olarak değiştikleri belirlenecektir. Böylece modelde kullanılan parametrelerin deprem analojisinde nelere karşılık geldiği tartışlacaktır. Bunun yanında RSF yasaları da karşılaştırılacaktır. Çünkü her ne kadar bu yasalar, laboratuvarda ve simülasyonlarda benzer sonuçlar üretseler de farklı sürtünme tanımlarına dayanmaktadırlar. Dolayısıyla sismik yer hareketi, gerilim yüklemesi veya başka tür tetikleyici etkiler araştırılırken, RSF yasalarındaki farklılıkların ciddi anlamda sonuçlara etki edebileceği öngörülmektedir. Bu karşılaştırma önemlidir, çünkü bu çalışmada kullanılan model daha sonra güçsüz sinyallerin depremleri ne yönde tetikleyeceğini gösteren çalışmalarda kullanılacaktır.

\section{Yöntem}

\subsection{Hız-ve-Durum Sürtünme Yasaları}

RSF yasasının sürtünme ve gerilime ilişkin bağıntısı aşağıda verilmiştir.

$f=\left(\frac{\tau}{\sigma}\right)=f_{0}+\Theta+\operatorname{aln}\left(\frac{v}{V_{0}}\right)$

Burada sırasıyla $f, \tau, \sigma, f_{0}, a, v$ ve $V_{0}$, sürtünme katsayısı, kayma gerilimi, normal gerilim, referans sürtünme sabiti, materyal sabiti, blok hızı ve referans hızı temsil etmektedir. (1) numaralı denklemin tanımlanabilmesi için iki yüzey arasındaki tutma gücünün veya gerçek pürüzlü temas eden yüzeyi ifade eden durum (state) parametresinin tanımlanması gerekmektedir. Üç farklı sürtünme yasası için durum parametresi $(\Theta)$, aşağıdaki bağıntılarla ifade edilmektedir.

$\frac{d \Theta}{d t}=\frac{b V_{0}}{L}\left[\exp \left(-\frac{\Theta}{b}\right)-\frac{v}{V_{0}}\right]$

$\frac{d \Theta}{d t}=-\frac{v}{L}\left[\Theta+b \ln \left(\frac{v}{V_{0}}\right)\right]$

$\frac{d \Theta}{d t}=\frac{b}{2 L}\left[V_{0} \exp \left(-\frac{\Theta}{b}\right)-\exp \left(\frac{\Theta}{b}\right) \frac{v^{2}}{V_{0}}\right]$

(2) numaralı denklemde sırasıyla Dieterich, Ruina ve Perrin tipi sürtünme yasaları için durum parametresinin bağıntıları verilmiştir. Denklemlerdeki $b$ ve $L$ parametreleri, materyal sabiti ve iki yüzey arasında yeniden bir durum parametresinin başlaması için gerekli olan kritik mesafelerdir. Üç sürtünme yasası da laboratuvar testlerinde birbirlerine yakın sonuçlar üretmelerine rağmen farklı sürtünme temellerine sahiptirler. Henüz hangi yasanın gerçeği daha iyi ifade edebildiği açık bir problemdir. Daha ayrıntılı bilgi için Marone (1998) çalışmasına bakılabilir. 


\subsection{Burridge-Knopoff Modeli}

BK modeli, sürtünmeli bir yüzey üzerinde bulunan $N$ adet bloğun $V_{0}$ referans hızlı sürücü bir blok ile çekilmesinden oluşan hareket denklemidir. Model, Şekil 1'de gösterilmiştir.

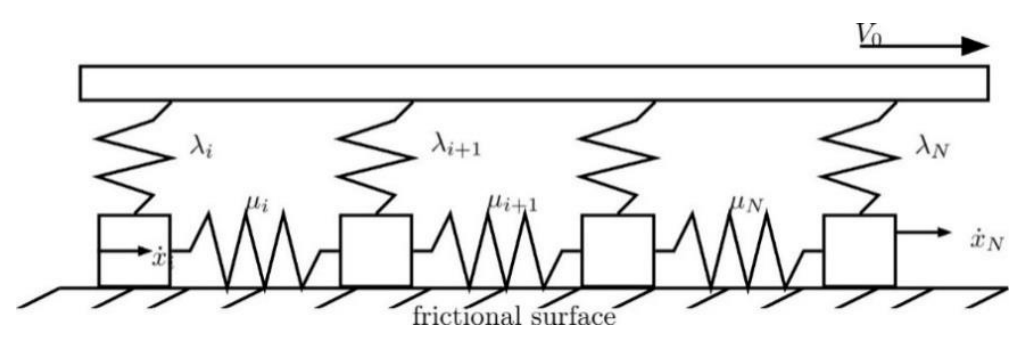

Şekil 1: Burridge-Knopoff yay-blok sistemi

Şekil 1'de $\lambda_{i}$ ve $\mu_{i}$ sırasıyla $i$. bloğa ait sürücü ve eşleşmeli blokların yay sabitlerini tanımlamaktadır. $x_{i}$ ve $\dot{x}_{i}$ değerleri $i$. bloğun boylamsal eksendeki konumunu ve hızını tanımlamaktadır. $\mathrm{V}_{0}$ referans hızını temsil etmektedir. Yani bloklar $\mathrm{V}_{0}$ hızı ile sürtünmeli düzlem üzerinde harekete zorlanmaktadır. Modelin hareket denklemi aşağıda verilmiştir.

$m_{i} \ddot{x}=\mu_{i}\left(x_{i+1}-2 x_{i}+x_{i-1}\right)-\lambda_{i}\left(x_{i}-V_{0} t\right)-F_{i}\left(\dot{x}_{l}, \Theta_{i}\right)$

Denklemde $m, \mu$ ve $\lambda$, sırasıyla kütle, sürücü ve eşleşmeli blokların yay sabitlerini temsil etmektedir. Yay sabitleri iki yüzey arasındaki elastik lineer özelliği tanımlamaktadır (Scholz, 2002). Yay sabiti için $\lambda=\mu \approx G / H$ bağıntısı kullanılabilir. Burada, $G$, kesme modülünü, $H$ ise fay yüzeyinin kalınlığını temsil etmektedir. Bu çalışma kapsamında fay kalınlığı ve derinliği eşit kabul edilmiştir. Tüm türevler zamana bağlıdır. $F_{j}\left(\dot{x}_{l}, \Theta_{i}\right)$, denklem (1)'de verilen sürtünme kuvvetini temsil etmektedir. Sistem üzerinde analizleri daha kolay yapabilmek için önce $x_{i}=u_{i}+V_{0} t$ bağıntısıyla, boylamsal konum, sürücü bloğa göre konumu şeklinde yeniden yazılabilir. Buradaki $t$ zamanı temsil etmektedir. Ayrıca $u=\bar{u} L, v=\bar{v} V_{0}, \Theta=$ $\bar{\Theta} a$ ve $t=T L / V_{0}$ parametreleri tanımlanarak sistem boyutsuzlaştırılır. Böylece (1) ve (3) denklemleri tekrar aşağıdaki şekilde tanımlanır.

$\ddot{\bar{u}}_{i}=\gamma_{\lambda}^{2}\left(\bar{u}_{i+1}-2 \bar{u}_{i}+\bar{u}_{i-1}\right)-\gamma_{\mu}^{2} \bar{u}_{i}-\frac{\gamma_{\mu}^{2}}{\xi}\left(\bar{f}+\bar{\Theta}_{i}+\ln \left(\bar{v}_{i}\right)\right)$

Denklemdeki, $\bar{u}, \bar{v}, \bar{\Theta}$ değişkenleri sırasıyla boyutsuzlaştırmış kayma, hız ve durum parametrelerini ifade etmektedir. $\gamma_{\lambda}=$ $\sqrt{\frac{\lambda}{m}} \frac{L}{V_{0}}$ ve $\gamma_{\mu}=\sqrt{\frac{\mu}{m}} \frac{L}{V_{0}}$ parametreleri boyutsuzlaştırılmış frekansları, $\xi=\frac{\mu L}{\sigma a}$ parametresi boyutsuzlaştırılmış yay sabitini ve $\bar{f}=f / a$ parametresi sürtünme sabitini ifade etmektedir. (4) numaralı denklemi tamamlamak için (2) numaralı denklemlerdeki durum değişkenlerine de aynı işlemler uygulanarak aşağıdaki şekilde ifade edilirler.

$\dot{\bar{\Theta}}_{i}=\beta\left[\exp \left(-\frac{\bar{\Theta}_{i}}{\beta}\right)-\left(\bar{v}_{i}\right)\right]$

$\dot{\bar{\Theta}}_{i}=-v_{i}\left(\bar{\Theta}_{i}+\beta \ln \left(v_{i}\right)\right)$

$\dot{\bar{\Theta}}_{i}=\frac{\beta}{2}\left[\exp \left(-\frac{\bar{\Theta}_{i}}{\beta}\right)-\exp \left(\frac{\bar{\Theta}_{i}}{\beta}\right) \bar{v}_{i}^{2}\right]$

(5) numaralı denklemler sırasıyla Dieterich, Ruina ve Perrin tipi sürtünme yasaları için boyutsuzlaştırılmış durum parametresinin bağıntılarıdır. Burada $\beta=b / a$ parametresi sürtünme ile bağlantılı hareketi zorlaştırıcı (work hardening) 
parametredir. (4) numaralı denklem ile (5) numaralı denklemlerden bir tanesi kullanılarak hareket denklemleri tanımlanmış olur. Denklemlerin boyutsuzlaştırılması ve sürtünme yasaları hakkında daha ayrıntılı bilgi Nakatani (2001), Erickson vd. (2008) ve Erickson, Birnir ve Lavallée (2011)'den elde edilebilir.

\subsection{Tek Serbestlik Dereceli Model}

Tek blok için hareket denklemi yazıldığında, (4) ve (5) numaralı denklemler birinci dereceden adi diferansiyel denklem şeklinde aşağıdaki gibi yazılır.

$\dot{\bar{u}}=\bar{v}-1$

$\dot{\bar{v}}=-\gamma^{2}\left[\bar{u}+\frac{(\bar{f}+\bar{\Theta}+\ln (\bar{v}))}{\xi}\right]$

$\dot{\bar{\Theta}}=-\bar{v}(\bar{\Theta}+\beta \ln (\bar{v}))$

(6) numaralı denklemlerde Ruina tipi sürtünme yasası sunulmuştur. Başka bir sürtünme yasası için, durum parametresinin türevi (5) numaralı denklemdeki bağıntılardan herhangi biri ile değiştirilebilir. Bu haliyle sistem sadece tek bloğun sürtünmesinden kaynaklı oluşan dinamikleri sergilemektedir. Bu dinamiklerden, periyodik (sismik döngü) ve kararlı hareketler Şekil 2'de gösterilmiştir.

Kararlı durumda sistem belirli bir süre salınım yaparak sabit noktaya gitmektedir (Şekil 2- Sağ grafik). Sistemin sürtünme kararlıllğı veya kararsızlığı ile ilgili analiz üçüncü bölümde anlatılmıştır. Sürtünme kararsızlı̆ğ olduğu durumda periyodik bir hareket görülmektedir. Periyodik hareket, hızlı ve yavaş zaman olarak ikiye ayrılabilir. Sistem yavaş zamandayken blok uzun süre düşük bir hız ile (referans hızına yakın) gerilim biriktirir. Bu sürede sürtünme düzlemindeki bloğun tutabilme gücünü gösteren durum parametresi de zamanla artar. Sistem hızlı zaman dilimindeyken ise yayda biriken gerilim ani bir hareket ile salınır, hız parametresi sivrilir, durum parametresi aniden düşer ve sürtünmeli blok sürücü bloğa yaklaşır. Ancak bloktaki ani değişim nedeniyle hız değişkeninin sıfira çok hızlı yaklaştı̆̆ durumda, (6) numaralı denklemdeki logaritmik ifade bir matematik hatası verecektir. Özellikle hız değişimi $-\gamma^{2} / \xi$ parametresine bağlıdır. Gerçek bir fay boyutu için $\gamma$ parametreleri $10^{4}-10^{12}$ arasında değerler almaktadır (Erickson vd., 2008). Bu değer sistemin sertliğini arttırmakta ve modeli gerçekçi parametreler ile çözmeyi zorlaştırmaktadır. Nümerik hesaplama sırasında çok küçük integral adımları kullanılsa dahi, açık (explicit) yöntemler sistemi çözmekte başarısız olabilirler. Bu çalışmada, sistemin çözümü için iki farklı çok adımlı kapalı (implicit) nümerik integral alma yöntemi birlikte kullanılmıştır. Sistem yavaş bir şekilde evrilirken AdamBashforth-Moulton yöntemi kullanılmış, sistem hızlı zamana geçtiğinde ise daha sert diferansiyel denklemler için uygun olan geri yönde diferansiyel "Backward Differentiation” yöntemi uygulanmıştır. İki yöntemin birlikte kullanılabilmesi için her adımda sistemin sertlik hesaplamasının yapılması gerekmektedir. (6) numaralı denklemin Jacobi matrisinin her nümerik entegrasyon adımında hesaplanması ve özdeğerlerinin bir önceki durum ile karşılaştırılması gerekmektedir. Bu durum ayrıca işlem yükü getirmesine rağmen, sistemin dinamikleri göz önüne alındığında ve bu çalışmadaki deneysel gözlemlere göre, sistemin çözümü için uygun ve etkili bir algoritma olduğu görülmüştür. Yöntem hakkında daha ayrıntılı bilgi için Petzold (1983) çalışmasına bakılabilir.

\section{Bulgular}

\subsection{RSF Yasalarının Tek Serbestlik Dereceli Modelde Karşılaştırılması}

(6) numaralı denklemin üç sürtünme yasası için sadece bir sabit noktası vardır $\left(\bar{u}^{*}, \bar{v}^{*}, \bar{\Theta}^{*}=0,0,1\right)$ ( $f$ sürtünme sabiti, 
sistemin kararlılık analizinde etkili olmadığı için 0 kabul edilmiştir). Dolayısıyla doğrusal kararlılık analizi için (6) numaralı denklemin sabit noktadaki Jacobi matrisi (7) numaralı denklemdeki gibi hesaplanır.

$$
\left[\begin{array}{ccc}
0 & 1 & 0 \\
-\gamma^{2} & -\frac{\gamma^{2}}{\xi} & -\frac{\gamma^{2}}{\xi} \\
0 & -\beta & -1
\end{array}\right]
$$
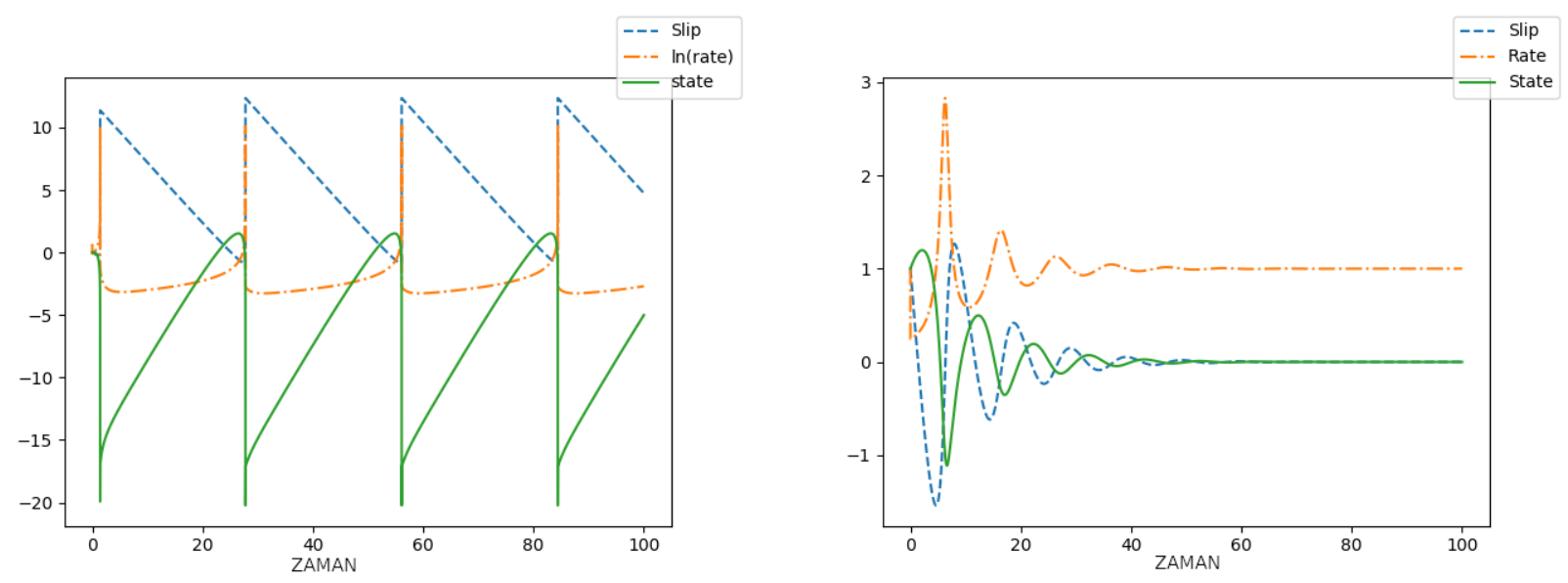

Şekil 2: Sismik periyodik döngü ve kararlı hareketi gösteren grafik: (Yatay eksen zamanı temsil etmektedir. Sol taraftaki grafikte sürtünme kararsızlığından kaynakı oluşan sismik döngü gösterilmektedir. Bu döngüye göre, hız değerinin doğal logaritması (turuncu çizgi) uzun süre sıfıra yakındır. Bu dönem yavaş zaman olarak adlandırıır. Bu sürede, gerilim birikimi (mavi kesikli çizgi) ve iki yüzey arasındaki tutunma gücünü ifade eden durum değişkeni (yeşil sürekli çizgi) artmaktadır. Daha sonra, biriken gerilim kritik bir eşiğe ulaşır ve yayda (fayda) biriken enerji hızla salınır. Bu aşamaya hızlı zaman denir. Bu aşamada hız değeri (turuncu) aniden sivrilir, durum parametresi (yeşil) ve biriken gerilim (mavi) düşer. Sağ taraftaki grafik kararı durumu göstermektedir. Sistem başlangıç konumundan kaynaklı gerilimi yavaş̧̧a salarak kararlı duruma ulaşmaktadır. Not: grafikte kayma, hız ve durum değişkenlerini daha iyi gösterebilmek için ölçek uygulanmıştır.)

Doğrusal kararlılık analizi için denklem 7'nin özdeğerleri incelenir. Eğer tüm özdeğerlerin reel kısımları negatif ise sistem kararlıdır. Bir tanesi ya da daha fazlası pozitif olduğu durumda sistem sabit noktası çevresinde kararlılığını kaybetmiş demektir. 7 numaralı matrisin özdeğerleri üçüncü dereceden karakteristik bir polinoma dönüştürülerek Routh Hurwitz ölçütü uygulanmıştır. Routh-Hurwitz ölçütüne göre sistemin özdeğerlerinin işaretini $\xi_{c r}=-\frac{\gamma^{2}(\beta-1)}{\beta-\gamma^{2}-1}$ bağıntısı kontrol etmektedir. Buradaki kararlı durumdan kararsız duruma geçiş bir Hopf çatallaşmasıdır (Strogatz, 2018). Gerçekçi bir fay için $\gamma$ parametresi $10^{4}-10^{12}$ aralarında değerler almakta, buna karşın $\xi \approx 0.5$ ve $\beta=1-3$ parametreleri görece düşük değerler almaktadır. $\gamma$ parametresinin çok büyük değerler aldığı göz önünde bulundurulursa sistemin kritik durumunu belirten bağıntı $\xi_{c r} \approx \beta-1$ şeklinde sadeleştirilebilir. Böylece, bu çalışmada bulunan bağıntı Gu vd. (1984)'te atalet terimi göz ardı edilerek bulunan bağıntı ile aynı olmuş olur.

Sistemin sabit noktasında model parametreleri değiştirilerek hesaplanan özdeğerlerine ait grafik Şekil 3’te verilmiştir.

Şekil 3'te özdeğerlerin parametrelere göre değişimini gösteren grafik, Routh-Hurwitz ölçütüne göre bulunan bağıntıyı doğrulamaktadır. Sistem RSF parametreleri $\beta$ ve yay sabiti $\xi$ değerlerine bağlı olarak kararlı ya da kararsız duruma geçmektedir. $\gamma$ parametresinin değişiminin, kararlılık analizindeki etkisi azdır. Sadece çok küçük olduğu durumda dinamikleri büyük ölçüde etkilemektedir.

Hesaplanan kararlılık ölçütü kullanılarak üç RSF yasası kıyaslanmıştır. Kıyaslama sonucu sistem kararlı durumdayken üç yasanın da benzer sonuçlar ürettiği görülmüştür (Şekil 4). $\xi$ ve karşılık gelen $\beta$ parametreleri yeterince büyük olduklarında 
ise, Perrin yasası, Dieterich ve Ruina yasasından farklı bir yörünge çizdiği görülmüştür (Şekil 5). Dieterich yasasının, Ruina yasasına göre daha uzun süre salınım yaparak sabit noktaya ulaştığı görülmüştür. Perrin yasasının $\beta$ ve $\xi$ değerleri büyük olduğu durumda, kararlılık kriterine uymamış olmasının sebebi doğrusallaştırma işlemi sırasında göz ardı edilen doğrusal olmayan terimleri olabilir.
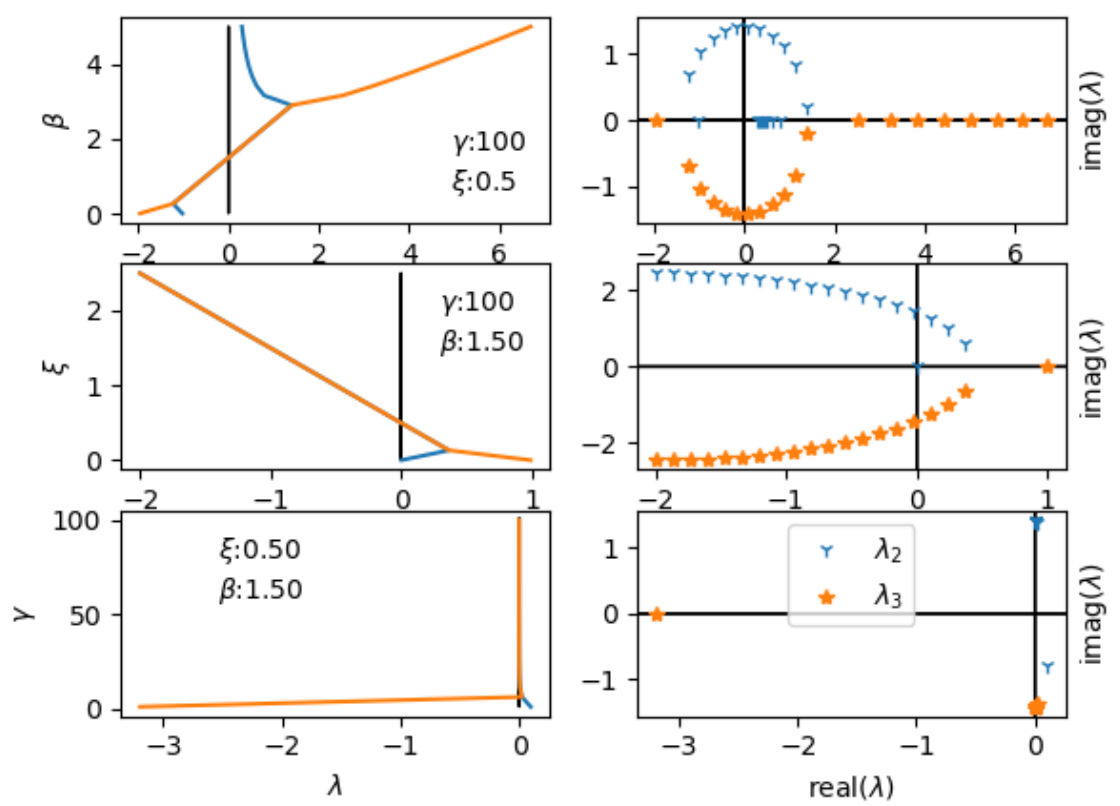

Şekil 3: Parametre değişimine göre sistemin kararlılık durumunun değişimini gösteren şekil: (Yukarıdan aşağı doğru sırasıyla $\beta$, ६, $Y$ parametreleri değiştirilip diğer parametreler sabit tutularak özdeğerlerin işaret değiştirdiği kritik değerler incelenmiştir. Yatay eksenin işaret değiştirdiği yerler siyah çizgi ile gösterilmiştir. Sol tarafta yatay eksen olarak özdeğerlerin $(\lambda)$ reel kısımları sırasıyla $\beta, \xi, y$ parametrelerine göre çizilmiştir. Sağ tarafta ise bu değerlere ait reel ve sanal değerleri çizilmiştir. Sistemin reel değerinin işaret değiştirmesi sistemin kararlı durumdan, kararsız duruma geçişini gösterir. Not: özdeğerlerin bir tanesi kesin olarak negatif olduğu için geri kalan iki özdeğer şekilde gösterilmiştir.)

Sistem $\xi \leq \xi_{c r}$ durumda sürtünme kararsızlığı sergilemektedir (Şekil 6). Sürtünme kararsızlığ1 olduğu durumda, sistem periyodik bir limite yaklaşmaktadır. Şekil 6'da RSF yasaları karşılaştırıldığında, ilgili periyodik limitin büyükten küçüğe doğru sıralaması Perrin, Dieterich ve Ruina yasası şeklindedir. Ruina yasası en hızlı şekilde periyodik limite yakınsarken, Dieterich yasası en yavaştır. Sistem kararlı durumdan çıktığında, doğrusal kararlılık analizi, sistemin nasıl davranacağı konusunda yeterli bilgiyi vermez. Bunun için doğrusal olmayan analizler gereklidir. Ancak bu çalışma kapsamında doğrusal olmayan analizler yapılmamış, bunun yerine RSF yasalarına göre simülasyon yapılmıştır.

\subsection{Simülasyon}

$\mathrm{Bu}$ çalışma kapsamında Ruina tipi RSF yasasını kullanarak BK modelinin simülasyonu gerçekleştirilmiştir. Simülasyonda fay geometrisi sabit kabul edilerek sadece RSF parametrelerinin etkileri araştırılmıştır. Simülasyonda kullanılan parametreler Parkfield bölgesi çalışmalarında kullanılan ve kestirilenlere yakın değerlerdir.

Parkfied, yaklaşık 22 yıllık yarı periyodik yapısı nedeniyle, deprem çalışmaları için en ilgi çeken yerlerden birisidir. Bu nedenle yaklaşık $50 \mathrm{~km}$ uzunluğundaki sağ yönlü ve eğim açısı 90 dereceye yakın olan doğrultu atımlı fay çevresi jeodezik ve sismik ağlarla donatılmıştır. Son deprem 2004 yılında gerçekleşmiştir. Bu depremin derinliği yaklaşı $5-6 \mathrm{~km}$ olup, $12 \mathrm{~km}$ uzunluğundaki kısmında kırılma gerçekleşmiştir. Kosismik depremin neden olduğu en yüksek deformasyon $60 \mathrm{~cm}$ civarındadır (Johnson vd., 2006; Savage \& Langbein, 2008; Barbot vd., 2009; Helmstetter \& Shaw 2009; Chang vd., 2013). 

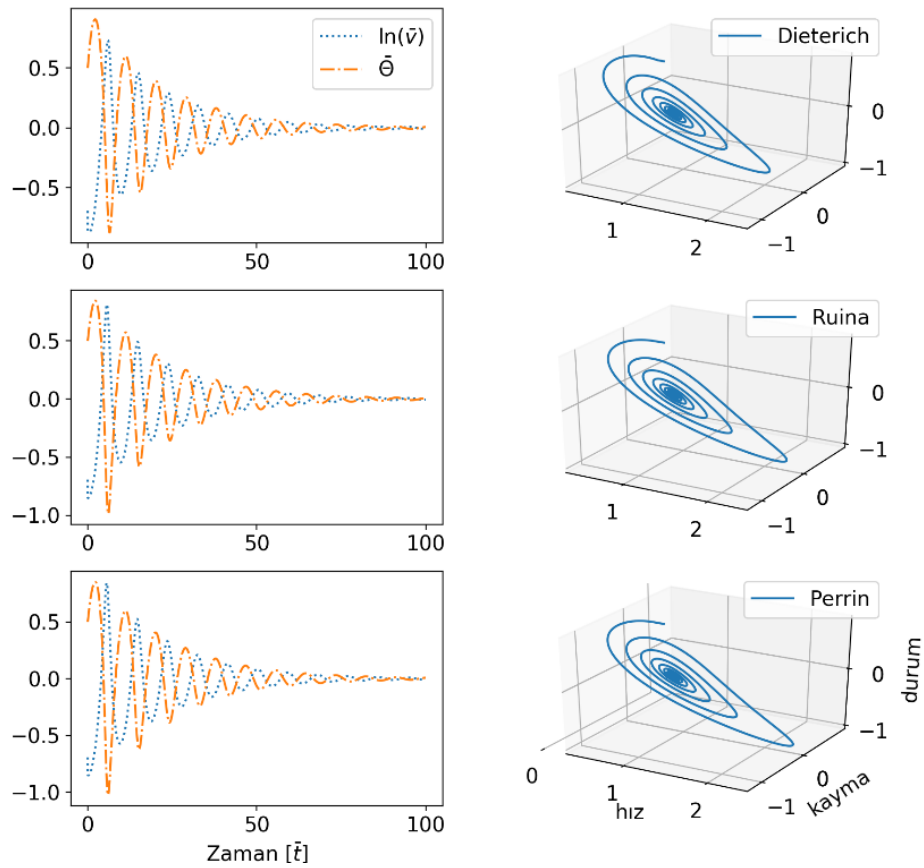

Şekil 4: RSF yasalarının (sırasıyla Dieterich, Ruina ve Perrin yasaları) $\xi>\xi_{\text {cr }}$ Ölçütüne göre kararlı durumunda karşılaştırılması: (Sol tarafta, sırasıyla üç farklı yasanın (Dieterich, Ruina ve Perrin) aynı başlangıç parametreleriyle, yatay eksende zaman ve dikey eksende logaritmik hız ve durum değişkenleri görülmektedir. Iki değişken de gerilimin salınmasıyla birlikte kararlı duruma ulaşmaktadır. Sağ taraftaki grafik ise faz çizimini göstermektedir. Faz çizimleri değişkenlerin birbirlerine göre durumlarını ifade etmektedir. Buradaki değişkenler sırasıyla yatayda hız ve kayma (yatay eksen) ve dikeyde durum değişkenleridir. Sistem kararlı olduğunda bu üç değişken sırasıyla $(1,0,0)$ kararlı duruma doğru ilerleyen bir yörünge çizmektedir. Not: grafikteki zaman, hız, kayma ve durum parametreleri boyutsuzlaştırılmış değerlerdir.)

$\gamma: 100 \xi: 1.50 \beta: 2.40$
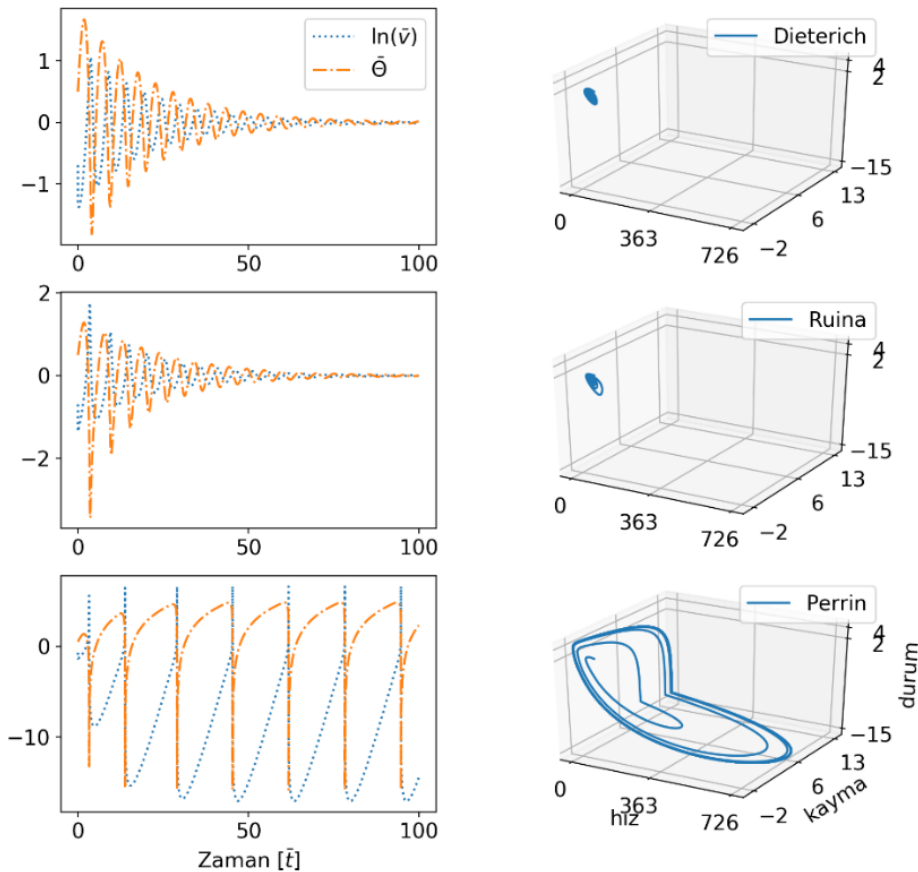

Şekil 5: RSF yasalarının (sırasıyla Dieterich, Ruina ve Perrin yasaları) $\xi>\xi_{c r}$ ölçütüne göre kararlı durumunda ama $\xi$ - $\beta$ parametrelerinin yeterince büyük olduğu durumda karşılaştırılması. (Çizimdeki eksenler ve çizgi tipleri (4) numaralı şekilde açıklanmıştır. Dieterich ve Ruina yasaları kararlı kayma hareketi gösterirken, Perrin yasası sürtünme kararsızlığı göstermiştir. Not: grafikteki zaman, hız, kayma ve durum parametreleri boyutsuzlaştırılmış değerlerdir.) 
Simülasyon için sürücü hız $V_{0}=35 \mathrm{~mm} / y l l$, litosfer yoğunluğu $\rho=2700 \mathrm{~kg} / \mathrm{m}^{3}$, kesme modülü $G=30 \mathrm{GPa}$ olarak sabit kabul edilmiştir. Bu parametreler Tullis'in (1996), Parkfield fayının simülasyonunda kullandığı parametrelerdir. Henüz hangi RSF parametrelerinin deprem analojisini tam olarak yansıttığı bilinmemektedir. Bu çalışmada, $a \in(0.006-0.008)$ ve $b \in(0.007-0.015)$, sürtünme için kritik uzaklık $L \in(0.001-0.05) m$ ve efektif normal gerilim $\sigma_{n} \in$ (50 - 100) $M P a$ arasında değiştirilmiştir. Simülasyonda kullanılan parametreler özet halinde (1) numaralı tabloda sunulmuştur.
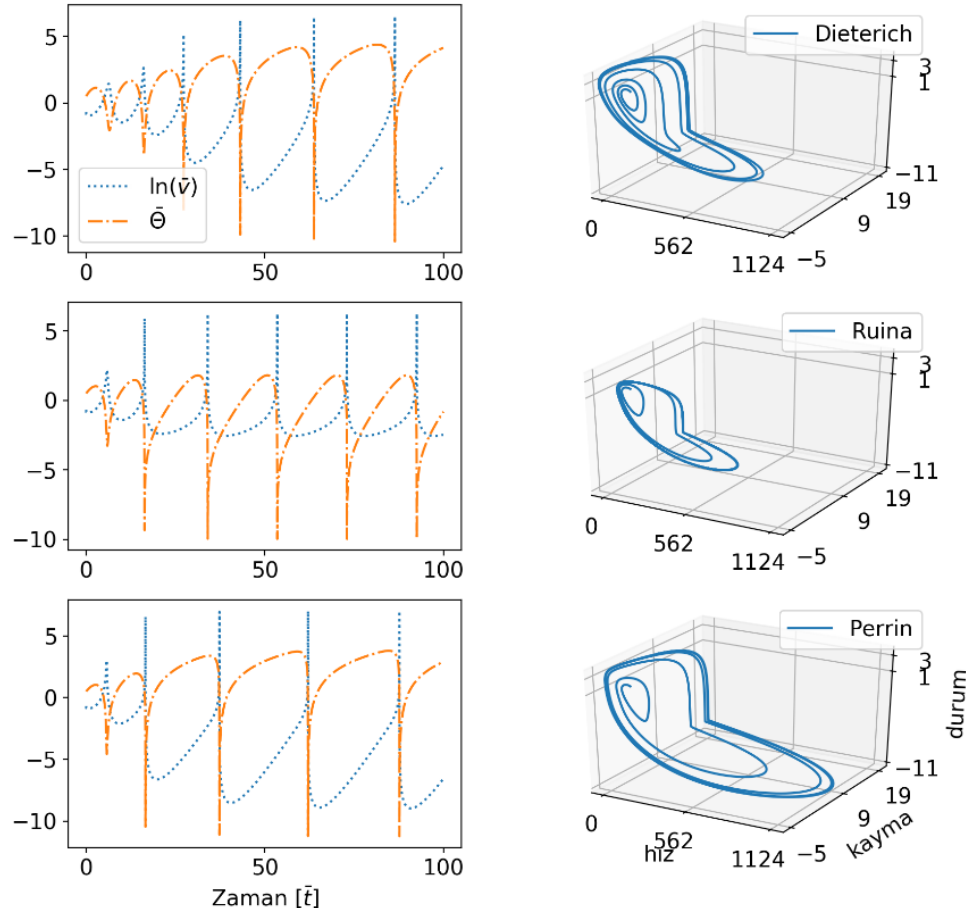

Şekil 6: RSF yasalarının (sırasıyla Dieterich, Ruina ve Perrin yasaları) $\quad \xi \leq \xi_{c r}$ ölçütüne göre sürtünme kararsızlığı durumunda karşıllaştırılması: (Çizimdeki eksenler ve çizgi tipleri (4) numaralı şekilde açıklanmış̧ır. Üç yasa da sürtünme kararsızı̆̆ı nedeniyle kararı periyodik davranış sergilemiştir. Dieterich yasası daha yavaş periyodik limite ulaşırken, en hızı Ruina yasası ulaşmışır. Periyodik limitler büyüklügü bakımından karşılaştırılığında Perrin, Dieterich ve Ruina yasası şeklindedir. Not: grafikteki zaman, hız, kayma ve durum parametreleri boyutsuzlaştırılmış değerlerdir.)

Tablo 1: Simülasyonda kullanılan parametreler

\begin{tabular}{|c|c|c|c|c|c|c|c|c|}
\hline $\mathbf{a}$ & b & $\mathbf{L}(\mathbf{m})$ & $\begin{array}{c}\mathrm{V0} \\
(\mathrm{mm} / \mathrm{y})\end{array}$ & $\begin{array}{c}\sigma_{\mathbf{n}} \\
(\mathbf{M P a}) \\
\end{array}$ & $\begin{array}{c}\text { Derinlik } \\
(\mathbf{k m})\end{array}$ & $\begin{array}{c}\text { Uzunluk } \\
(\mathbf{k m})\end{array}$ & $\begin{array}{c}\mathbf{G} \\
(\mathbf{G P a}) \\
\end{array}$ & $\begin{array}{c}\text { Yoğunluk } \\
\left(\mathbf{k g} / \mathbf{m}^{3}\right)\end{array}$ \\
\hline $0.006-0.008$ & $0.007-0.015$ & $0.001-0.05$ & 35 & $50-100$ & 6 & 12 & 30 & 2700 \\
\hline
\end{tabular}

Simülasyon sonucu kayma, hız, dinamik-statik gerilim ve sismik periyot ya da tekrarlanma zamanı gibi sonuçlar kaydedilmiştir. Bunlardan kayma değeri 50-70 cm arasında olanlar (2) numaralı tabloda sunulmuştur. Tabloya göre sonuçlar, Parkfield depremi değerlerinden uzaktırlar. Özellikle hız değerleri beklenenden çok daha düşük çıkmıştır. Bu uyuşumsuzluğun sebeplerinden birisi yay sabiti değeri olabilir. Bu çalışmada fay yüzeyinin genişliği ve derinliği eşit kabul edilerek $\left(\mathrm{H}=6 \mathrm{~km}, \lambda=\mu \approx \frac{30 \mathrm{GPa}}{6000 \mathrm{~m}}=5 \mathrm{MPa} / \mathrm{m}\right)$ değerleri hesaplanmıştır. Turcotte ve Schubert (2014) kırılgan kabukta olan faylar için fay yüzeyinin 75 m-7.5 km arasında değerler alabileceğini hesaplamıştır. Bu çalışmada kullanılan değerler hesaplanan aralık içerisindedir. Ancak, yay-blok sistemi ve RSF yasaları ile yapılan diğer yayınlarda, Roy ve Marone (1996) yay sabitini 1-5 GPa/m, Gomberg vd. (1997) ve Belardinelli vd. (2003) $12.5 \mathrm{MPa} / \mathrm{m}$ olarak kullanmışlardır. Dolayısıyla yay 
sabiti olarak belirlenen değerler arasında ciddi farklar vardır. Ayrıca laboratuvar ortamında oluşturulan RSF parametrelerinin doğadaki karşılıkları tam olarak bilinememektedir. Bunların yanında tek serbestlik dereceli bir model ile yapılan simülasyonlar ile depremlerin karmaşı ilişkilerini modellemek fazla iyimserliktir. Yine de, (2) numaralı tabloda bulunan sonuçlar RSF parametrelerinin deprem analojisine etkilerini açıklamak için kullanılabilir.

Tablo 2: Simülasyon sonuçları

\begin{tabular}{|c|c|c|c|c|c|c|c|c|c|c|c|c|}
\hline $\mathbf{a}$ & b & $\mathbf{L}(\mathbf{m})$ & $\begin{array}{c}\text { N_gerilim } \\
(\mathbf{P a})\end{array}$ & gamma & $\mathbf{x i}$ & beta & fs & fd & $\begin{array}{c}\text { Kayma } \\
(\mathbf{m})\end{array}$ & $\begin{array}{c}\begin{array}{c}\text { Hiz } \\
(\mathbf{m} / \mathbf{s n})\end{array} \\
\end{array}$ & $\begin{array}{c}\text { Periyot } \\
\text { (yıl) }\end{array}$ & $\begin{array}{c}\text { D_gerilim } \\
\text { (Pa) }\end{array}$ \\
\hline 0.0060 & 0.007 & 0.001 & 75000000 & 111 & 0.01 & 1.17 & 0.11 & 0.09 & 0.52 & 0.00003 & 7.7 & 1449000 \\
\hline 0.0060 & 0.008 & 0.001 & 50000000 & 111 & 0.02 & 1.33 & 0.11 & 0.08 & 0.59 & 0.00004 & 8.6 & 1638500 \\
\hline 0.0070 & 0.008 & 0.001 & 75000000 & 111 & 0.01 & 1.14 & 0.11 & 0.09 & 0.55 & 0.00003 & 8.1 & 1530750 \\
\hline 0.0070 & 0.009 & 0.001 & 50000000 & 111 & 0.02 & 1.29 & 0.11 & 0.08 & 0.61 & 0.00004 & 8.9 & 1702500 \\
\hline 0.0070 & 0.008 & 0.001 & 100000000 & 111 & 0.01 & 1.07 & 0.11 & 0.09 & 0.50 & 0.00003 & 7.4 & 1340000 \\
\hline 0.0080 & 0.009 & 0.001 & 75000000 & 111 & 0.01 & 1.12 & 0.11 & 0.09 & 0.58 & 0.00004 & 8.5 & 1608750 \\
\hline 0.0060 & 0.007 & 0.002 & 100000000 & 223 & 0.02 & 1.17 & 0.11 & 0.09 & 0.68 & 0.00004 & 10.1 & 1910000 \\
\hline 0.0060 & 0.008 & 0.002 & 50000000 & 223 & 0.04 & 1.33 & 0.11 & 0.08 & 0.55 & 0.00003 & 8.2 & 1554500 \\
\hline 0.0070 & 0.008 & 0.002 & 75000000 & 223 & 0.02 & 1.14 & 0.11 & 0.09 & 0.52 & 0.00003 & 7.8 & 1457250 \\
\hline 0.0070 & 0.009 & 0.002 & 50000000 & 223 & 0.03 & 1.29 & 0.11 & 0.08 & 0.58 & 0.00003 & 8.5 & 1617500 \\
\hline 0.0080 & 0.009 & 0.002 & 75000000 & 223 & 0.02 & 1.12 & 0.11 & 0.09 & 0.55 & 0.00003 & 8.2 & 1533000 \\
\hline 0.0060 & 0.007 & 0.004 & 100000000 & 446 & 0.04 & 1.17 & 0.11 & 0.09 & 0.64 & 0.00004 & 9.6 & 1806000 \\
\hline 0.0060 & 0.008 & 0.004 & 50000000 & 446 & 0.07 & 1.33 & 0.11 & 0.08 & 0.51 & 0.00003 & 7.7 & 1462000 \\
\hline 0.0070 & 0.008 & 0.004 & 100000000 & 446 & 0.03 & 1.14 & 0.11 & 0.09 & 0.67 & 0.00004 & 10.2 & 1911000 \\
\hline 0.0070 & 0.009 & 0.004 & 50000000 & 446 & 0.06 & 1.29 & 0.11 & 0.08 & 0.53 & 0.00003 & 8.1 & 1523000 \\
\hline 0.0070 & 0.009 & 0.004 & 75000000 & 446 & 0.04 & 1.20 & 0.11 & 0.08 & 0.69 & 0.00004 & 10.3 & 1944000 \\
\hline 0.0080 & 0.009 & 0.004 & 75000000 & 446 & 0.04 & 1.12 & 0.11 & 0.09 & 0.51 & 0.00003 & 7.8 & 1443000 \\
\hline 0.0060 & 0.007 & 0.006 & 100000000 & 669 & 0.05 & 1.17 & 0.11 & 0.09 & 0.60 & 0.00003 & 9.3 & 1736000 \\
\hline 0.0070 & 0.008 & 0.006 & 100000000 & 669 & 0.05 & 1.14 & 0.11 & 0.09 & 0.64 & 0.00004 & 9.9 & 1838000 \\
\hline 0.0070 & 0.009 & 0.006 & 50000000 & 669 & 0.09 & 1.29 & 0.11 & 0.08 & 0.50 & 0.00003 & 7.8 & 1460500 \\
\hline 0.0070 & 0.009 & 0.006 & 75000000 & 669 & 0.06 & 1.20 & 0.11 & 0.08 & 0.65 & 0.00004 & 10.0 & 1872000 \\
\hline 0.0080 & 0.009 & 0.006 & 100000000 & 669 & 0.04 & 1.12 & 0.11 & 0.09 & 0.67 & 0.00004 & 10.4 & 1934000 \\
\hline 0.0060 & 0.007 & 0.010 & 100000000 & 1115 & 0.09 & 1.17 & 0.11 & 0.09 & 0.54 & 0.00003 & 8.8 & 1628000 \\
\hline 0.0060 & 0.009 & 0.010 & 50000000 & 1115 & 0.18 & 1.50 & 0.11 & 0.07 & 0.67 & 0.00004 & 10.4 & 1958000 \\
\hline 0.0070 & 0.008 & 0.010 & 100000000 & 1115 & 0.08 & 1.14 & 0.11 & 0.09 & 0.58 & 0.00003 & 9.4 & 1724000 \\
\hline 0.0075 & 0.009 & 0.010 & 75000000 & 1115 & 0.10 & 1.20 & 0.11 & 0.08 & 0.59 & 0.00003 & 9.5 & 1763250 \\
\hline 0.0080 & 0.009 & 0.010 & 100000000 & 1115 & 0.07 & 1.12 & 0.11 & 0.09 & 0.61 & 0.00003 & 10.0 & 1815000 \\
\hline
\end{tabular}

Tabloda sırasıyla “a”, b" ve "L” değerleri RSF parametrelerini, "N_gerilim” sütunu normal gerilimi, "gamma”, "xi” ve "beta" sütunları $\gamma, \xi, \beta$ model parametrelerini, "fs" ve "fd” sütunları statik ve dinamik gerilimi, "kayma", "hız" ve "periyot” sütunları da kayma, hız ve sismik periyodu ve "D_gerilim” sütunu kayma sırasında salınan gerilimi belirtmektedir. Kayma, hız ve periyot değerleri doğru orantılı olarak değişmektedir. Simülasyon sonuçlarına göre çok sayıda RSF parametresinin $50-70 \mathrm{~cm}$ arasında kayma değeri oluşturabildiği görülmüştür. Sonuçlara göre fay geometrisi, normal gerilim ve diğer etkiler sabit kabul edildiğinde sistemin büyüklüğünü belirleyen ana etkenin $\beta$ ve $\xi$ parametreleri olduğu görülmüştür. Bu iki parametre "a", b" ve "L” RSF parametreleri ve iki yüzey arasındaki lineer elastik özelliği tanımlayan yay sabiti “ $\mu$ ” ve efektif gerilim “ $\sigma$ ” değerlerine göre değişmektedir $\left(\beta=\frac{b}{a}, \xi=\frac{\mu L}{\sigma a}\right.$.). Özellikle b/a oranı arttıkça sistemin sismik gücü artmakta, dolayısıyla periyot, hız ve gerilim gibi değerler de artmaktadır. Bunun yanında yayın sertliği “ $\mu$ ” veya kritik uzaklık "L” arttıkça sistem sismik olarak daha güçsüz hale gelmektedir. Tersi şekilde efektif normal gerilimin artması da sistemin sismik gücünü 
arttırmaktadır.

Şekil 7'de, sol taraftaki grafikte farklı $\xi$ ve $\beta$ parametrelerinin oluşturdukları dinamikler görülmektedir. Kullanılan $\xi$ ve $\beta$ parametre çiftlerini ve sismik ve sismik olmayan bölgeleri ayıran $\xi_{c r}$ eğrisi sağdaki grafikte gösterilmiştir. Grafikten de görüldüğü üzere farklı $\xi$ ve $\beta$ parametre çiftleri aynı dinamikleri üretmektedir. Bu parametreler $\xi_{c r}$ kritik eğrisinden eşit uzaklıkta seçilmiş̧ir (Şekil 7-Sağ grafik). Tablo 1'den ve Şekil 7'den de anlaşılacağı üzere sistemin ya da depremin büyüklüğü $\xi_{c r}$ kritik eğrisinden uzaklığıyla orantılıdır. Buradaki sonuç Helmstetter ve Shaw (2009)'un tartıştı̆̆ basit yayblok sistemi kullanarak deprem verilerine uygun çok sayıda RSF parametresinin kestirilebileceği ifadesini desteklemektedir. Ayrıca $\beta$ ve $\xi$ parametreleri sabit kabul edildiğinde, sistemin ürettiği büyüklüğün $\gamma$ frekans parametresi ile ters, normal gerilim ile doğru orantılı olduğu görülmüştür.
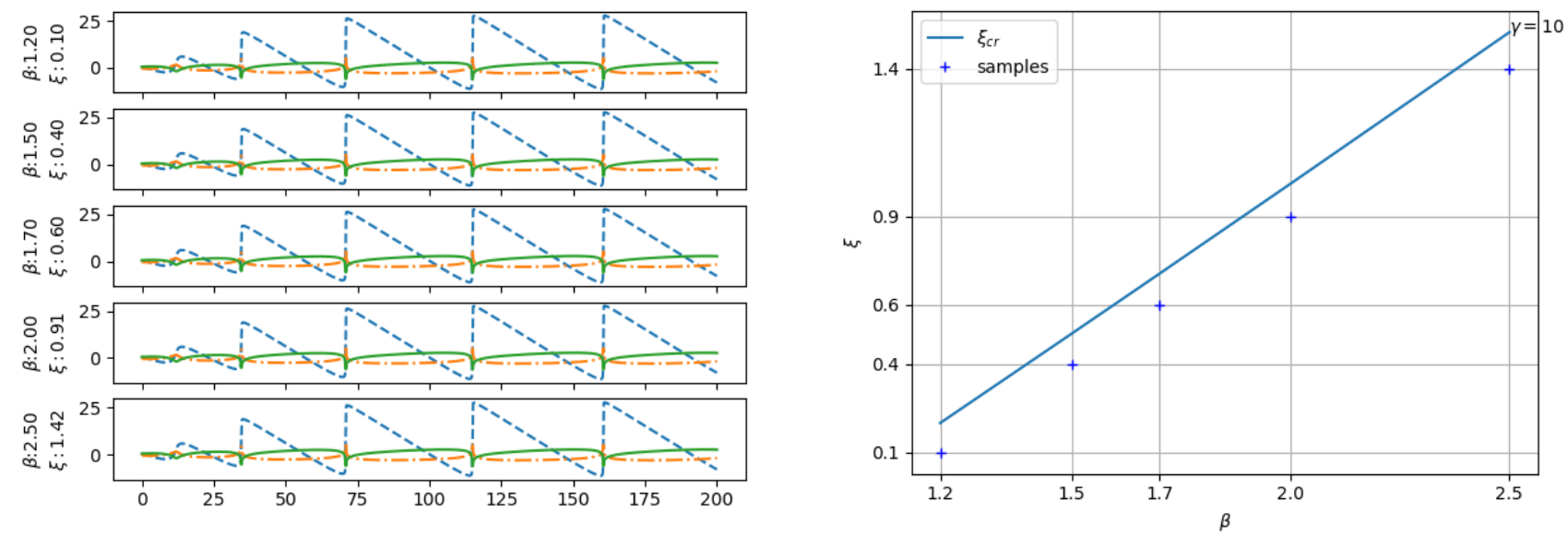

Şekil 7: Farklı parametreler ile aynı dinamiklerin elde edildiğini gösteren grafik: (Sol tarafta farklı $\beta$ ve $\xi$ parametreleri kullanılmasına rağmen sistemin aynı sonuçları ürettiği görülmektedir. Burada mavi kesik çizgiler kayma değerlerini, turuncu ile gösterilen çizgi hızın doğal logaritmik değerini, yeşil düz çizgi ise durum parametresini göstermektedir. Sağ taraftaki grafikte ise, sol taraftaki hesaplamalarda kullanılan ( $\beta$, $\xi)$ parametre çiftlerinin çizim görülmektedir. Buradaki eğri $\gamma=10$ değerine göre çizilen $\xi_{c r}$ kritik değeridir. Bu kritik eğriden $\xi=\xi_{c r}-0.1$ kadarlık sapmalar (+) işareti ile çizilmiştir. Grafikten anlaşılacağı gibi kritik eğriden sabit bir sapma olduğunda, sistemde aynı dinamikler görülmektedir.)

\section{Sonuç ve Öneriler}

$\mathrm{Bu}$ çalışma kapsamında Dieterich, Ruina ve Perrin RSF yasaları tek serbestlik dereceli BK modeli kullanılarak karşılaştırılmıştır. Öncelikle çalışılan sistemin kararlılık analizi yapılarak, analitik bir bağıntı bulunmuştur. Üç sürtünme yasası da bulunan bağıntıya göre analiz edilmiştir. Sistem kararlı durumdayken RSF yasaları birbirlerine çok benzer dinamikler sergilemiştir. Sürtünme parametresi $\beta$ ve yay sabitini belirleyen $\xi$ parametresi yeterince büyük olduğunda ise Perrin yasası, Dieterich ve Ruina yasasından farklı sonuçlar üretmiş̧ir. Bu farklılığın sebebi, Perrin yasasında sistemin doğrusallaştırma işlemi sırasında göz ardı edilen diğer doğrusal olmayan terimlerinden kaynaklı olabileceği şeklinde yorumlanmıştır.

Kararlılık analizi sadece sistem sabit noktaya yakın olduğu durumda dinamiklerle ilgili bilgi vermektedir. Sistem sabit noktadan uzaklaştığında ve sürtünme kararsızlığı sergilediğinde dinamikler hakkında bilgi edinebilmek için sistem simüle edilmiştir. Simülasyonda kullanılan parametreler 2004 Parkfield depremine yakın olarak seçilmiştir ve sadece RSF parametrelerinin etkileri araştırılmıştır. Elde edilen sonuçlardan bazıları (2) numaralı tabloda sunulmuştur. Tabloda sunulan değerler ile doğada gözlenen değerler hakkında yakın bir karşılaştırma yapılamamıştır. Çünkü yapılan basitleştirme her ne kadar deprem analojisini temel anlamda karşılasa da diğer taraftan birçok önemli karmaşık detayı hesaba katmamaktadır. Yine de tabloda sunulan sonuçlar belirli parametrelerin ve değişkenlerin deprem olayını ne yönde etkilediği ile ilgili önemli 
bilgiler vermektedir. Sonuçlara ve Şekil 7 sağ taraftaki grafiğe göre, deprem büyüklüğünün $\xi_{c r}$ kritik eğrisinden sapmasıyla orantılı olduğu görülmüştür ( $\gamma$ parametresinin yeterince büyük olduğu durumlar için eğri $\xi_{c r}=\beta-1$ şeklinde doğrusal olmaktadır). Şekil 7 sağdaki eğrinin altta kalan kısmı sismik bölgeleri, üstte kalan kısımları ise kararlı kaymanın olduğu bölgeleri göstermektedir. Bu eğriden aşağı tarafa doğru uzaklaştıkça sistemin üreteceği dinamiklerin büyüklüğü (hız, kayma, salınan gerilim ve dolayısıyla depremin büyüklüğ̈̈) artmakta, tersi şekilde yukarı doğru uzaklaştıkça, sistemin kararlı duruma ulaşmasının hızı artmaktadır.

Şekil 7'de görüldüğü üzere kritik eğriden sabit oranda sapma olduğunda, farklı RSF parametreleri kullanılmış olsa da sistem aynı sonuçları üretmektedir. Dolayısıyla doğadaki bir kayma hareketini tanımlayabilecek sonsuz sayıda RSF parametresi bulunabilmektedir. Bu durum Helmstetter ve Shaw (2009) çalışmasında bahsettiği çok sayıdaki RSF parametresinin 2004 Parkfield depremi verilerinden RSF yasaları ve basit yay-blok sistemi kullanılarak kestirilebileceğini açıklamaktadır. Çalışmada RSF parametreleri olarak, literatürde kullanılan kestirilen parametrelere yakın değerler kullanılmıştır. Yine de hangi parametrelerin doğada gözlenenler için uygun olduğu açık bir problemdir.

Bu çalışmada sistemin sadece kararlı olduğu ya da sabit noktanın kararlılığını kaybederek çatallaşma sonucu oluşan limit döngüye yaklaştığı dinamikler sunulmuştur. Bunların yanında kritik eğriden uzaklaştıkça sistemin limit döngüsü de kararlılığını kaybedebilmektedir. Ayrıca belirli parametre aralığında tek serbestlik dereceli modelde periyot ikilemeleri şeklinde farklı periyotlar gözlenerek sistem daha sonra kaotik davranmaktadır. Ancak, belirtilen kararsız limit döngü ve kaotik davranışlar bu çalışmada incelenmemiştir (Gu vd., 1984; Erickson vd., 2008).

Sonuç olarak, depremi tek serbestlik dereceli bir bloğun gerçekçi bir sürtünme kuvveti etkisindeki dinamik hareketleri şeklinde basitleştirmek, belirli parametrelerin veya kuvvetlerin etkisini araştırmak bakımında yararlı olacaktır. Özellikle yakın faylarda gerçekleşen bir deprem diğer depremleri tetikleyebilmektedir. Diğer depremin tetiklenmesi sonucu oluşan deprem tekrarlama zamanındaki (recurrence time) gecikme ve öne alma, sistemin sismik döngüsüne doğrusal olmayan bir şekilde bağlıdır. Sistem doğrusal olarak çözüldüğünde gözlenemeyecek birtakım olaylar ise doğrusal olmayan dinamik sistemlerde gözlenebilmektedir (Gomberg vd., 1997; Strogatz, 2018). Tekrarlama zamanındaki gecikme ve öne alma ilişkisi bu olaylardan birisidir. Bunların yanında, RSF yasaları her ne kadar laboratuvarda benzer sonuçlar üretmiş olsalar da farklı fiziksel temellere sahiptirler. Literatürde RSF yasaları kullanılarak deprem tetiklemesi üzerine çalışmalar yapılmıştır. Ancak bahsedilen çalışmalarda RSF yasalarından kaynaklanabilecek farklılıklar incelenmemiştir. Bu çalışma ileride başka depremlerin veya yer kabuğundaki gel-git ve benzeri güçsüz sinyallerin depremi ne yönde etkileyeceği konulu araştırmalara fayda sağlayacaktır.

\section{Kaynaklar}

Barbot, S., Fialko, Y., \& Bock, Y. (2009). Postseismic deformation due to the Mw 6.02004 Parkfield earthquake: Stress-driven creep on a fault with spatially variable rate-and-state friction parameters. Journal of Geophysical Research: Solid Earth, 114(B7).

Belardinelli, M. E., Bizzarri, A., \& Cocco, M. (2003). Earthquake triggering by static and dynamic stress changes. Journal of Geophysical Research: Solid Earth, 108(B3).

Burridge, R., \& Knopoff, L. (1967). Model and theoretical seismicity. Bulletin of the seismological society of america, 57(3), 341-371.

Chang, S. H., Avouac, J. P., Barbot, S., \& Lee, J. C. (2013). Spatially variable fault friction derived from dynamic modeling of aseismic afterslip due to the 2004 Parkfield earthquake. Journal of Geophysical Research: Solid Earth, 118(7), 3431-3447.

Dieterich, J. H. (1979). Modeling of rock friction: 1. Experimental results and constitutive equations. Journal of Geophysical Research: Solid Earth, 84(B5), 2161-2168.

Erickson, B., Birnir, B., \& Lavallée, D. (2008). A model for aperiodicity in earthquakes. Nonlinear Processes in Geophysics, 15(1), 1-12. 
Erickson, B., Birnir, B., \& Lavallée, D. (2011). Periodicity, chaos and localization in a Burridge-Knopoff model of an earthquake with rate-and-state friction. Geophysical Journal International, 187(1), 178-198.

Gomberg, J., Blanpied, M. L., \& Beeler, N. M. (1997). Transient triggering of near and distant earthquakes. Bulletin of the Seismological Society of America, 87(2), 294-309.

Gu, J. C., Rice, J. R., Ruina, A. L., \& Simon, T. T. (1984). Slip motion and stability of a single degree of freedom elastic system with rate and state dependent friction. Journal of the Mechanics and Physics of Solids, 32(3), 167-196.

Helmstetter, A., \& Shaw, B. E. (2009). Afterslip and aftershocks in the rate-and-state friction law. Journal of Geophysical Research: Solid Earth, 114(B1).

Johnson, K. M., Burgmann, R., \& Larson, K. (2006). Frictional properties on the San Andreas fault near Parkfield, California, inferred from models of afterslip following the 2004 earthquake. Bulletin of the Seismological Society of America, 96(4B), S321-S338.

Kawamura, H., Ueda, Y., Kakui, S., Morimoto, S., \& Yamamoto, T. (2017). Statistical properties of the one-dimensional Burridge-Knopoff model of earthquakes obeying the rate-and state-dependent friction law. Physical Review E, 95(4), 042122.

Marone, C. (1998). Laboratory-derived friction laws and their application to seismic faulting. Annual Review of Earth and Planetary Sciences, 26(1), 643-696.

Nagata, K., Nakatani, M., \& Yoshida, S. (2012). A revised rate-and state-dependent friction law obtained by constraining constitutive and evolution laws separately with laboratory data. Journal of Geophysical Research: Solid Earth, 117(B2).

Nakatani, M. (2001). Conceptual and physical clarification of rate and state friction: Frictional sliding as a thermally activated rheology. Journal of Geophysical Research: Solid Earth, 106(B7), 13347-13380.

Perrin, G., Rice, J. R., \& Zheng, G. (1995). Self-healing slip pulse on a frictional surface. Journal of the Mechanics and Physics of Solids, 43(9), 1461-1495.

Petzold, L. (1983). Automatic selection of methods for solving stiff and nonstiff systems of ordinary differential equations. SIAM journal on scientific and statistical computing, 4(1), 136-148.

Roy, M., \& Marone, C. (1996). Earthquake nucleation on model faults with rate-and state-dependent friction: Effects of inertia. Journal of Geophysical Research: Solid Earth, 101(B6), 13919-13932.

Ruina, A. (1983). Slip instability and state variable friction laws. Journal of Geophysical Research: Solid Earth, 88(B12), 10359-10370.

Savage, J. C., \& Langbein, J. (2008). Postearthquake relaxation after the 2004 M6 Parkfield, California, earthquake and rate-and-state friction. Journal of Geophysical Research: Solid Earth, 113(B10).

Scholz, C. H. (1998). Earthquakes and friction laws. Nature, 391(6662), 37.

Scholz, C. H. (2002). The mechanics of earthquakes and faulting. Cambridge university press.

Strogatz, S. H. (2018). Nonlinear dynamics and chaos: with applications to physics, biology, chemistry, and engineering. CRC Press.

Tullis, T. E. (1996). Rock friction and its implications for earthquake prediction examined via models of Parkfield earthquakes. Proceedings of the National Academy of Sciences, 93(9), 3803-3810.

Turcotte, D., \& Schubert, G. (2014). Geodynamics. Cambridge university press. 